\title{
Receptor usage by the Acanthocheilonema viteae-derived immunomodulator, ES-62
}

\author{
William Harnett $^{\mathrm{a}, *}$, Helen S. Goodridge ${ }^{\mathrm{b}, 1}$, Janet M. Allen ${ }^{\mathrm{c}, 2}$, Margaret Harnett ${ }^{\mathrm{b}}$ \\ a Strathclyde Institute of Pharmacy and Biomedical Sciences, University of Strathclyde, Glasgow G4 ORE, UK \\ ${ }^{\mathrm{b}}$ Institute of Infection, Immunity and Inflammation, University of Glasgow, Glasgow G12 8TA, UK \\ ${ }^{\mathrm{c}}$ Division of Biochemistry and Molecular Biology, University of Glasgow, Glasgow G12 8QQ UK
}

\section{A R T I C L E I N F O}

Article history:

Received 26 April 2011

Received in revised form 17 July 2011

Accepted 1 September 2011

Available online $\mathrm{xxxx}$

\section{Keywords:}

ES-62

Filarial nematode

Phosphorylcholine

Surface receptor

\begin{abstract}
A B S T R A C T
ES-62 is an immunomodulatory phosphorylcholine (PC)-containing glycoprotein secreted by the rodent filarial nematode Acanthocheilonema viteae. Previously, the use of knockout mice has revealed the effects of ES-62 on macrophages and dendritic cells to be dependent on TLR4. However, it is possible that ES-62 may interact with additional proteins on the surfaces of target cells and hence that cells may vary with respect to receptor usage. In this study, we identified by molecular weight, proteins that interact with ES62 and found differences amongst the immune system cells studied. Thus, whereas lymphocytes appear to have two major interacting proteins of $\sim 135$ and $\sim 82 \mathrm{kDa}$, U937 monocytes only contain an ES-62binding protein of the latter molecular weight. Binding to the proteins on B cells and U937 cells was blocked by PC, suggesting a critical role for this ES-62 moiety in facilitating interaction. Finally, ES-62 binding is followed by internalization in both macrophages and B cells but only in the former was absence of TLR4 found to block internalization. These findings are consistent with differences in receptor usage by ES-62 amongst different cell-types.
\end{abstract}

(c) 2011 Elsevier Inc. All rights reserved.

\section{Introduction}

Parasitic helminths pose significant health problems for humans and also their domestic animals and livestock. This knowledge has resulted in widespread attempts to design vaccines and although these have been largely unsuccessful a great deal has been learned about the immunological relationship between helminth and host (reviewed in Maizels et al. (1999), Moreau and Chauvin (2010)). It is now clear that parasitic helminths have evolved a number of strategies for interfering with or modulating the immune system of the parasitized host (reviewed in Maizels and Yazdanbakhsh (2003)). Furthermore, a number of individual helminth products with immunomodulatory properties have now been defined (reviewed in Harnett and Harnett (2010)). A pattern, which is emerging is that these products are often anti-inflammatory and hence they have been studied in mouse models of diseases that are associated with inflammation in the search for novel anti-inflammatory drugs. This policy is consistent with the currently popular idea that parasitic worm infections may protect

\footnotetext{
* Corresponding author. Address: Strathclyde Institute of Pharmacy and Biomedical Sciences, 161 Cathedral Street, Glasgow G4 0RE, UK. Fax: +44 1415522562.

E-mail address: w.harnett@strath.ac.uk (W. Harnett).

Present address: Immunobiology Research Institute, Cedars-Sinai Medical Centre, Los Angeles, CA 90048, USA.

2 Present address: Biotechnology and Biological Sciences Research Council, Polaris House, North Star Avenue, Swindon, Wiltshire SN2 1UH, UK.
}

humans against the development of autoimmune and allergic diseases (reviewed in Helmby (2009)).

The possibility that defined helminth products could ultimately see use in the clinic argues for an understanding of their effects on the immune system at the molecular level. It would be prudent to establish for example, the identity of the receptors that they interact with and the effects that receptor ligation have on downstream signaling pathways. Certainly such information is beginning to emerge with respect to several defined helminth immunomodulators (reviewed in Everts et al. (2010), Harnett and Harnett (2010), Perrigoue et al. (2008), van Die and Cummings (2009)). One of these helminth molecules is ES-62, a secreted product of the rodent filarial nematode Acanthocheilonema viteae that is amongst the best characterized of the helminth-derived immunomodulators. It is a phosphorylcholine (PC)-containing molecule whose anti-inflammatory properties allow it to provide significant protection against the development of arthritis and allergy in mouse models and the PC moiety appears to be largely responsible for immunomodulatory activity (reviewed in Harnett and Harnett (2009)). Studies investigating the effects of ES-62 on antigen-presenting cells (APC) - macrophages and dendritic cells showed, via the use of knockout mice, that ES-62-induced immunomodulatory effects on these cells was dependent on the presence of MyD88 and TLR4 but not TLR2 (Goodridge et al., 2005). The reliance on TLR4 appeared atypical in that unlike bacterial LPS, ES62 was found to be active against APC obtained from $\mathrm{C} 3 \mathrm{H} / \mathrm{HeJ}$ mice, which have a point mutation in TLR4. PC conjugated to ovalbumin 
(OVA) can mimic ES-62's effects on APC and this is also dependent on both MyD88 and TLR4 and like ES-62, PC-OVA is also effective in C3H/HeJ mice (Goodridge et al., 2007).

Although ES-62 activity in APC has been shown to be dependent on TLR4, this is not the only potential cell surface receptor for it. Thus, ES-62, possibly via its high mannose glycan moiety (Haslam et al., 1997), has been found to bind a soluble form of the mannose receptor and we also have some evidence suggesting that, perhaps as befits a PC-containing molecule, it is able to interact with cells via the PAF receptor (unpublished results). Although we have yet to put biological significance to these additional interactions ((Goodridge et al., 2007) and unpublished results) they clearly indicate the possibility of multiple receptor usage by ES-62. Furthermore, it is possible that different cells of the immune system may bind ES-62 via distinct receptors or alternatively, differential TLR4-containing receptor complexes. In relation to this, in this manuscript we examine receptor usage by ES-62 on lymphocytes and myeloid cells and we present evidence to suggest that the receptors that ES-62 uses varies amongst cell types.

\section{Materials and methods}

\subsection{ES-62, mice and cells}

Purified ES-62 from A. viteae was prepared as described previously (Goodridge et al., 2005). Wild type BALB/c and C57BL/6 mice were obtained from Harlan Olac (Bicester, UK). TLR4 ${ }^{-l-}$ and MyD88 $^{-1-}$ mice (C57BL/6 background) were a generous gift from Prof. S. Akira, University of Osaka, Osaka, Japan to Dr. K. Else and Dr. S. Tötemeyer at the Universities of Manchester and Cambridge, UK, respectively. Mice and gerbils (used in production of ES-62) are housed and employed in experiments as indicated under home office licenses obtained from the UK government. Bone marrow-derived macrophages (bmMs) were prepared as described previously (Goodridge et al., 2004). Murine B cells ( $>98 \% \mathrm{sIg}^{+}$) were prepared using the CD43-magnetic bead negative-selection method of Miltenyi Biotec as described previously (Deehan et al., 2001). U937 cells, WEHI-231 B cells and Jurkat T cells were cultured as described previously (Harnett et al., 1998; Katz et al., 2004; Smith et al., 2003).

\subsection{Biacore analysis}

Analysis was carried out using CM5 research-grade biosensor chips in a biacore biosensor BIAcore 2000 (Uppsala, Sweden) as described previously (Mistrik et al., 2004). Briefly, ES-62 was immobilized on channels of CM5 chips using an amine coupling procedure and various membrane preparations screened for binding as indicated by an increase in the surface plasmon resonance (SRP) signal due to the alteration in refractive index caused by binding of a biomolecule(s) to the chip, followed by analysis of the dissociation phase. The fourth channel of the chip was left uncoated and used as the control reference cell to allow subtraction of background/non-specific binding of the membrane preparations to the chips. The kinetics parameters were derived from obtained data using BIA evaluation software 3.1 (Biacore AB). In some experiments, the anti-PC antibody TEPC 15 was injected prior to membrane fractions to determine whether the PC-moiety of ES-62 was important for binding.

\subsection{Preparation of whole cell lysates for Far Western blotting}

Cells were pelleted by centrifugation at $400 \mathrm{~g}$ for $10 \mathrm{~min}$, resuspended in $150 \mu \mathrm{l}$ lysis buffer pH 7.5 (100 mM Tris base, $300 \mathrm{mM}$ $\mathrm{NaCl}, 4 \%(\mathrm{v} / \mathrm{v}) \mathrm{NP} 40,0.5 \%(\mathrm{v} / \mathrm{v})$ sodium deoxycholate, 2 mM EDTA) containing $1 \mu \mathrm{g} / \mathrm{ml}$ each of chymostatin, leupeptin, antipain and pepstatin A and $1 \mathrm{mM}$ sodium orthovanadate and $10 \mathrm{mM}$ PMSF and solubilized on ice for $20 \mathrm{~min}$. Cellular debris was removed by microfugation at $10,000 \mathrm{rpm}$ for $10 \mathrm{~min}$ and the supernatants containing the solubilized whole cell lysates resolved by SDS-PAGE. For Far Western blotting, a biotin conjugate of ES-62 was used in place of the primary antibody and was then detected by an HRPconjugated anti-biotin antibody (diluted 1:2000 in wash buffer containing $5 \%$ Marvel). Immunoreactive bands were visualized by the enhanced chemiluminescence (ECL) system (Amersham, Buckinghamshire, UK).

\subsection{Biotinylation of cell surface proteins and preparation of membrane extracts}

Cells $\left(10^{8}\right)$ were washed three times and then resuspended in $0.5 \mathrm{ml}$ PBS pH 7.2. Freshly prepared NHS-biotin solution (Pierce) at $4 \mathrm{mg} / \mathrm{ml}$ was added and the cells were incubated at room temperature for $30 \mathrm{~min}$ on a rocking platform before washing three times in PBS to remove any unbound biotin. The cells were then resuspended in $1.5 \mathrm{ml}$ of ice-cold extraction buffer (50 mM HEPES $\mathrm{pH}$ 7.4, 5 mM CaCl$, 140 \mathrm{mM} \mathrm{NaCl}, 1 \%$ (v/v) octyl- $\beta$-D-glucopyranoside, $1 \mathrm{mM}$ PMSF, $1 \mathrm{mM}$ aprotonin, $1 \mathrm{mM}$ leupeptin) and snap frozen in liquid nitrogen. The sample was then thawed, homogenized in a glass homogeniser (20-30 strokes) and incubated on ice for $1 \mathrm{~h}$. The extract was then centrifuged at $2000 \mathrm{rpm}$ to pellet nuclei and unbroken cells and the resulting supernatant centrifuged at $45,000 \mathrm{~g}$ for $1 \mathrm{~h}$ at $4{ }^{\circ} \mathrm{C}$ and the supernatant retained as the solubilized membrane extract. For precipitation of ES-62-binding proteins, extracts were precleared by the addition of $50 \mu \mathrm{l}$ of $50 \%$ protein L-agarose washed slurry followed by incubation for $1 \mathrm{~h}$ at $4{ }^{\circ} \mathrm{C}$ on a rotator. Samples were microfuged at $13,000 \mathrm{rpm}$ for $10 \mathrm{~min}$ and the pellet discarded. ES-62-FITC $(5 \mu \mathrm{g} / \mathrm{ml})$ was added to the supernatant and incubated for $2 \mathrm{~h}$ at $4{ }^{\circ} \mathrm{C}$ on a rotator. The samples were then incubated with anti-FITC antibodies pre-bound to protein L-agarose ( $1 \mu \mathrm{g} / 50 \mu \mathrm{l} 50 \%$ protein L-agarose slurry) overnight at $4{ }^{\circ} \mathrm{C}$ on a rotator. In some experiments, the biotinylated membranes were preincubated with fucose, PC or an RGDS peptide in an attempt to block binding between ES-62 and polypeptides. The immune complexes were washed three times in PBS pH 7.2, resuspended in SDS-PAGE loading buffer, heated to release the proteins and the beads removed by microfugation prior to resolution of ES-62-binding proteins by SDS-PAGE and detection by an HRP-conjugated anti-biotin antibody.

\subsection{Preparation of cell extracts for Western blotting analysis of ES-62 binding to, and internalization via, TLR4}

Following incubation of the cells with ES-62 $(2 \mu \mathrm{g} / \mathrm{ml})$ at $37^{\circ} \mathrm{C}$, the cells were washed three times with ice cold $25 \mathrm{mM}$ Tris- $\mathrm{HCl}$ $\mathrm{pH} 7.4$ containing $150 \mathrm{mM} \mathrm{NaCl}$ and $100 \mathrm{mM}$ sodium orthovanadate before preparing cell lysates with RIPA buffer as described previously (Feng et al., 1999) and protein concentrations were determined using the microBCA protein assay reagent (Pierce, Rockford, USA). Cell lysates were resolved using the NuPAGE (Invitrogen) and transferred to nitrocellulose according to the manufacturer's instructions. Nitrocellulose filters were then incubated with wash buffer (2 M Tris, pH 7.5 containing $500 \mathrm{mM} \mathrm{NaCl}$ and $0.1 \%$ (v/ v) Tween-20) containing $5 \%$ milk protein for at least $1 \mathrm{~h}$ to block non-specific protein binding. The primary antibodies (rabbit antiES-62 serum) were diluted 1:100 in wash buffer containing 5\% Marvel and applied to the filter for $1 \mathrm{~h}$ at room temperature or overnight at $4{ }^{\circ} \mathrm{C}$. Following washing, the blots were incubated with HRP-conjugated anti-rabbit IgG (diluted 1:2000 in wash buffer containing $5 \%$ Marvel) for $1 \mathrm{~h}$ at room temperature (Egan et al., 2006). Immunoreactive bands were visualized by the 


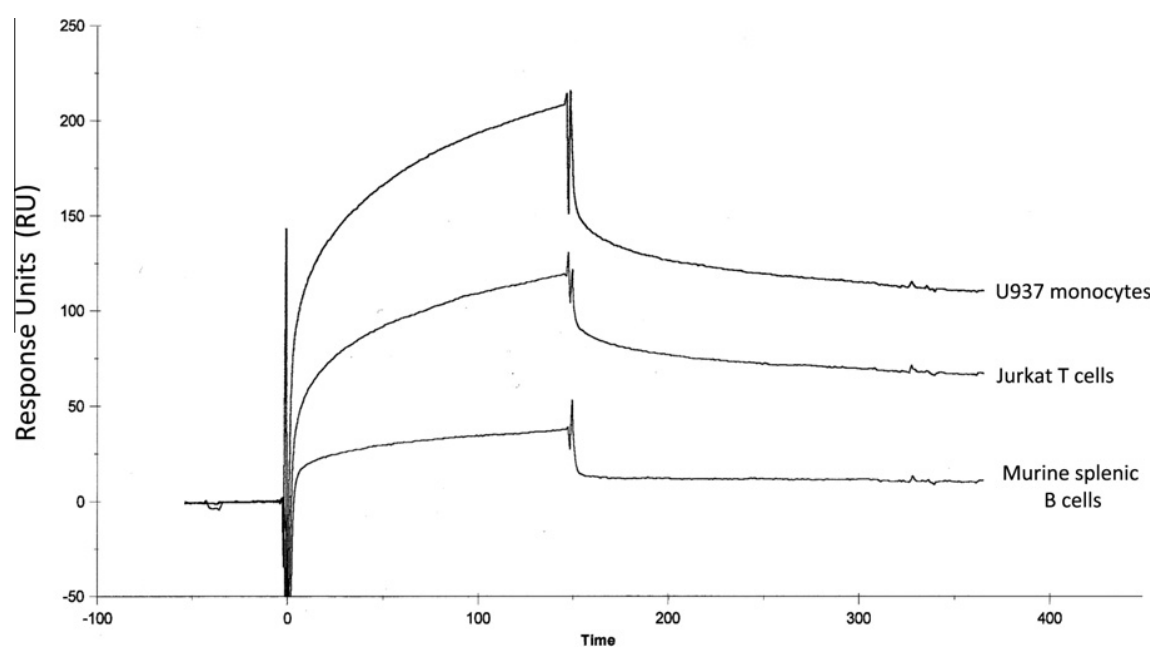

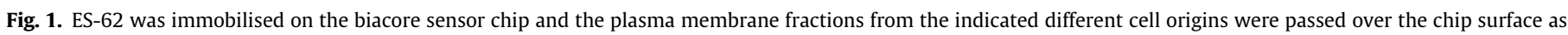
analyte. Regeneration was achieved using $100 \mathrm{mM}$ glycine.

enhanced chemiluminescence (ECL) system (Amersham, Buckinghamshire, UK).

\subsection{Immunofluorescence}

Bone marrow-derived macrophages (BMM; $10^{3}$ ) were incubated in $1 \mathrm{ml}$ of Dulbecco's modified eagle medium containing penicillin $(100 \mathrm{U} / \mathrm{ml})$, streptomycin $(100 \mu \mathrm{g} / \mathrm{ml}), 2 \mathrm{mM}$ glutamine and $10 \%$ heat-inactivated fetal calf serum (FCS) (DMEM-complete) on $13 \mathrm{~mm}$ coverslips in the wells of a 24 well-plate overnight at $37{ }^{\circ} \mathrm{C}$ in an atmosphere of $5 \% \mathrm{CO}_{2} / 95 \%$ air. The medium was removed and replaced with $1 \mathrm{ml}$ of DMEM-complete containing ES$62(2 \mu \mathrm{g} / \mathrm{ml})$ and incubated for a further $3 \mathrm{~h}$. The medium containing ES-62 was removed and the cells fixed in 3\% paraformaldehyde/ PBS containing $0.05 \%$ Triton $\mathrm{X}-100$ for $20 \mathrm{~min}$ at room temperature. Following fixing, the cells were washed $(\times 2)$ with PBS containing $1 \%$ FCS and then incubated with PBS containing 10\% FCS for $15 \mathrm{~min}$ at room temperature to prevent subsequent non-specific binding of antibody. The cells were then again washed $(\times 2)$ and incubated with KK6-FC4.3, a mouse monoclonal antibody against ES-62 or mouse IgG $(10 \mu \mathrm{g} / \mathrm{ml})$ in PBS containing $1 \%$ FCS for $2 \mathrm{~h}$ at room temperature. Following washing $(\times 4)$, cells were incubated with FITC-labeled goat anti-mouse IgG (dilution as recommended by manufacturer: Sigma, Poole, Dorset, UK) for 90 min at room temperature, washed again $(\times 4)$ and coverslips mounted on slides for examination by confocal fluorescence microscopy.

\subsection{Internalization of $\left[{ }^{35}\right.$ S]-methionine-labeled ES-62 and analysis of resultant labeled cellular cytosolic fractions}

WEHI-231 B cells $\left(10^{7}\right)$ per time-point were incubated in a 24 well plate in $1 \mathrm{ml}$ of RPMI 1640 medium supplemented with 5\% heat-inactivated fetal calf serum, penicillin $(100 \mathrm{U} / \mathrm{ml})$ and streptomycin $(100 \mu \mathrm{g} / \mathrm{ml}) . \quad\left[{ }^{35} \mathrm{~S}\right]-$ methionine-labeled ES-62 $\quad(50 \mu \mathrm{l}$; $\sim 15,000 \mathrm{cpm}$ ), prepared as described previously (Houston et al., 1997) was added to each well and the cells incubated at $37{ }^{\circ} \mathrm{C}$ in $5 \% \mathrm{CO}_{2} / 95 \%$ air for the appropriate times. Cells were washed $(\times 3)$ with RPMI medium supplemented as before and transferred to centrifuge tubes. Cells were then washed twice with $10 \mathrm{ml}$ ice-cold Tris-buffered saline (TBS) $\mathrm{pH} 7.6$, pelleted by centrifugation at $1500 \mathrm{~g}$ for $5 \mathrm{~min}$ and washed with $1 \mathrm{ml}$ TBS before being transferred to an Eppendorf tube and pelleted again as before. Cytosolic fractions were then prepared according to the nuclear and cytoplasmic extract kit commercially available from active motif and radioactivity of duplicate $10 \mu \mathrm{l}$ aliquots determined using a liquid scintillation counter.

\section{Results}

\subsection{Biacore analysis of ES-62 interaction with plasma membrane extracts of different cell types}

The kinetics of binding of ES-62 to molecules in plasma membrane extracts of monocytes, B cells and T cells was investigated by biacore analysis. This was undertaken by immobilizing ES-62 on the sensor chip and then employing the plasma membranes as analyte. As the kinetics of binding are reflected by the shape of the curve whilst the response units are equivalent to the mass bound, then the observed differences in both parameters likely indicate differences in receptor usage amongst the three cell types. However, as we were using membranes rather than purified proteins, the relative abundance of the individual proteins in the membranes derived from the distinct cell types may confound conclusions regarding the mass of protein bound, indicating that the kinetics are likely to be a better reflection of the differential receptor usage. The curves obtained are indeed suggestive of specific binding consistent with receptor-ligand interactions (Fig. 1) although as mentioned, precise binding kinetics cannot be measured, due to the analyte being impure and a mixture of membrane components. Nevertheless, the variation in the shape of the curve is suggestive of different kinetics of interaction that depends on the source of the membrane, with immobilized ES-62.

\subsection{Identification of ES-62-binding proteins from different cell types}

Several approaches were adopted to determine the nature of ES-62-binding proteins in these different cell types. First, we employed a Far Western blotting procedure using biotinylated ES-62 to identify binding proteins in whole cell extracts. This revealed that in both splenic B cells and Jurkat T cells, ES-62 interacted with proteins of $\sim 135$ and $\sim 82 \mathrm{kDa}$ whereas in U937 monocytes, binding was only observed with a protein of $\sim 82 \mathrm{kDa}$ (Fig. 2A). Next, we immunoprecipitated ES-62-interacting membrane proteins from surface-biotinylated B cells and U937 cells and employed an anti-biotin-HRP antibody for their detection. As with the Far Western analysis we detected polypeptides of 135 and $82 \mathrm{kDa}$ with respect to B cells but only the $82 \mathrm{kDa}$ molecule in U937 cells (Fig. 2B). 
A

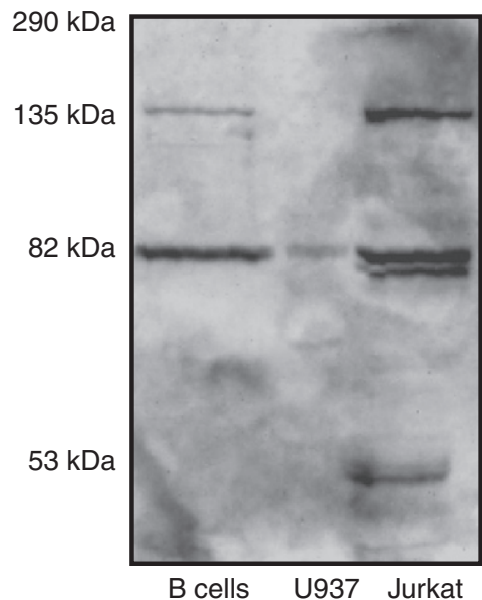

B

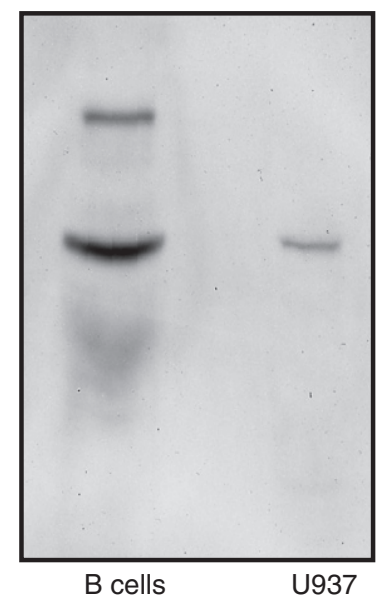

Fig. 2. (A) ES-62 interacting proteins in whole cell lysates from splenic B cells, U937 monocytes and Jurkat $\mathrm{T}$ cells were identified by Far Western blotting using biotinylated ES-62. (B) ES-62-interacting membrane proteins from surface biotinylated cells were immunoprecipitated and detected by Western blotting.

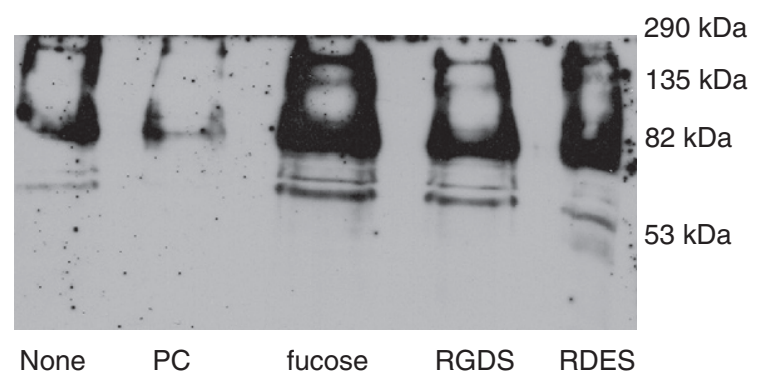

Fig. 3. Plasma membrane extracts from surface biotinylated WEHI-231 B cells were pre-incubated with medium or PC (1 mM), fucose (1 mM), RGDS (1 mM) or control RDES peptide $(1 \mathrm{mM})$ prior to incubation with ES-62-FITC and subsequent pulldown of ES-62-binding proteins using anti-FITC-bound protein L-agarose beads. ES62-binding proteins were then immunoprecipitated and detected by Western blotting.
The identity of the 82 and $135 \mathrm{kDa}$ proteins has yet to be established. The PAF and mannose receptors can be ruled out as they have predicted molecular weights of 39 and $166 \mathrm{kDa}$, respectively. The molecular weights of the detected proteins are roughly consistent both with integrin subunits ( 135 and $82 \mathrm{kDa}$ molecules) and toll-like receptors ( $82 \mathrm{kDa}$ molecule). Using the surface-biotinylated membrane extracts, we tested for the presence of integrins by determining whether fucose or an RGDS peptide could block interaction between ES-62 and the proteins in WEHI-231 B cell membranes (Kigimoto-Ochiai and Noguchi, 2000). However, we could find no evidence for the polypeptides being integrins (Fig. 3). Interestingly however free PC significantly inhibited binding to the two proteins thus demonstrating a likely role for the PC moiety of ES-62 in interactions with them. We also noted by biacore analysis that the anti-PC myeloma protein TEPC 15 prevented interaction between ES-62 and U937 proteins (Fig. 4). We had previously shown ES-62 activity to be dependent on TLR4 (Goodridge et al., 2005) and hence to determine whether the $82 \mathrm{kDa}$ polypeptide might be TLR4 we undertook Western blotting using an antiTLR4 antibody. The $82 \mathrm{kDa}$ molecule in U937 cells and Jurkat T cells was not recognized by the antibody whereas the $82 \mathrm{kDa}$ molecule in splenic B cells was weakly recognized by the antibody but in addition, by an anti-TLR2 antibody (results not shown). The results with the U937 and Jurkat T cells are perhaps not surprising as only $2 \%$ of the former express TLR4 (Romano Caratelli et al., 2010) and TLR4 is absent from the latter (Ye and Gan, 2007). The result with the B cells (which are known to express TLR4) may simply reflect cross-reactivity between antibodies but if this is the case and the molecule being detected is truly TLR4, then it would appear to be distinct from the $82 \mathrm{kDa}$ molecule being detected in the other cells.

\subsection{TLR4 is essential for internalization of ES-62 in macrophages but not $B$ cells}

Previously we have shown that ES-62 is internalized by mast cells (Melendez et al., 2007) and we now demonstrate by the use of immunofluorescence that the same is true of macrophages (Fig. 5A and B). Furthermore, incubation of B cells with $\left[{ }^{35} \mathrm{~S}\right]-$ methionine radiolabeled ES-62 and subsequent cell fractionation resulted in the molecule being clearly detected in a cytoplasmic extract within $1 \mathrm{~h}$ (Fig. 5C). Thus, our results as a whole indicate that

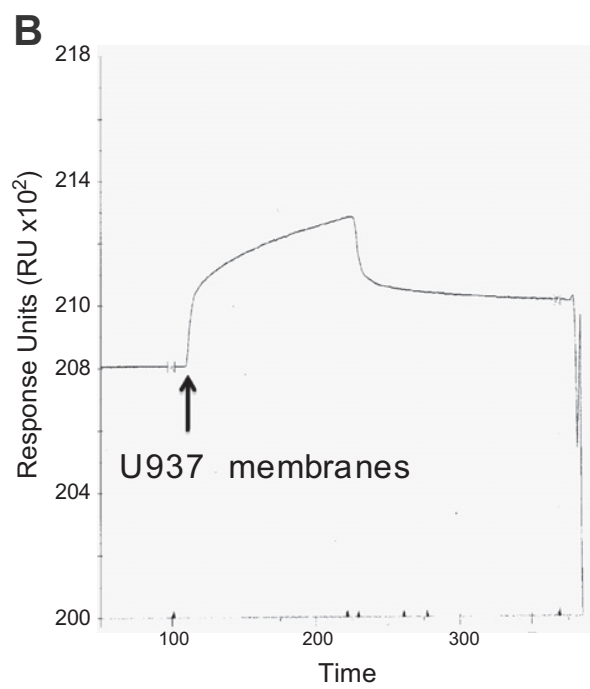

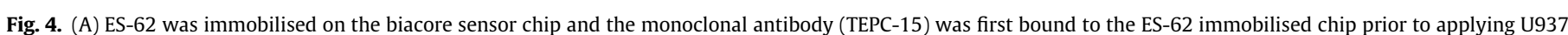

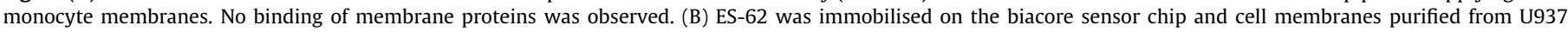
monocytes were passed over the chip surface as analyte. The expected binding curve (Fig. 1) for monocyte membranes was observed. 
A

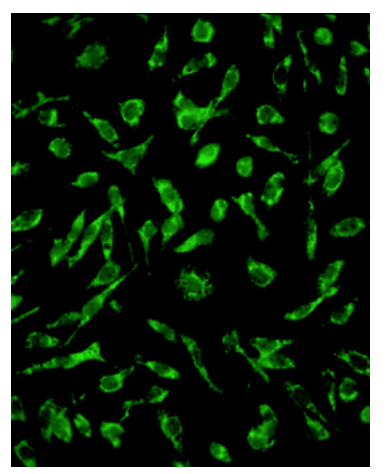

B

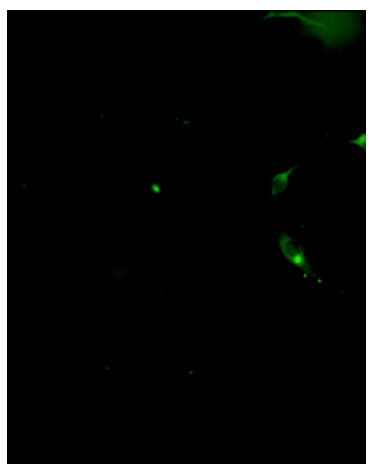

D

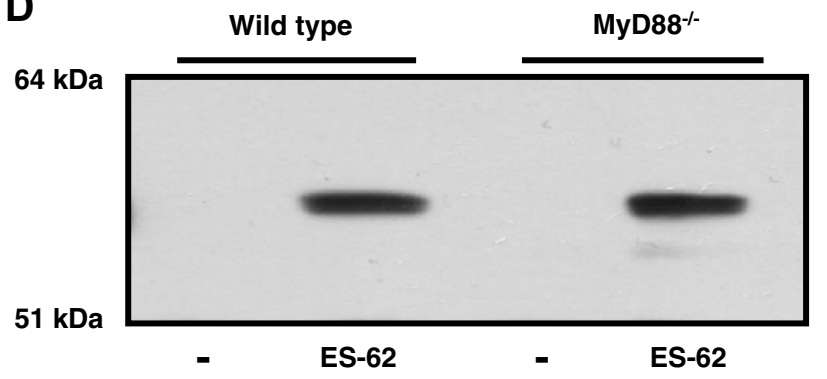

E

$64 \mathrm{kDa}$

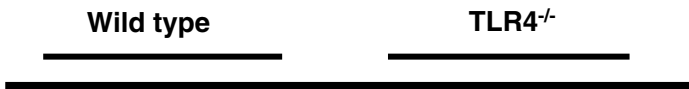

$51 \mathrm{kDa}$

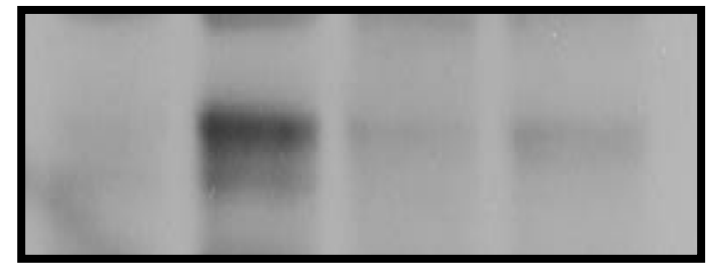

- $\quad$ ES-62

ES-62
C

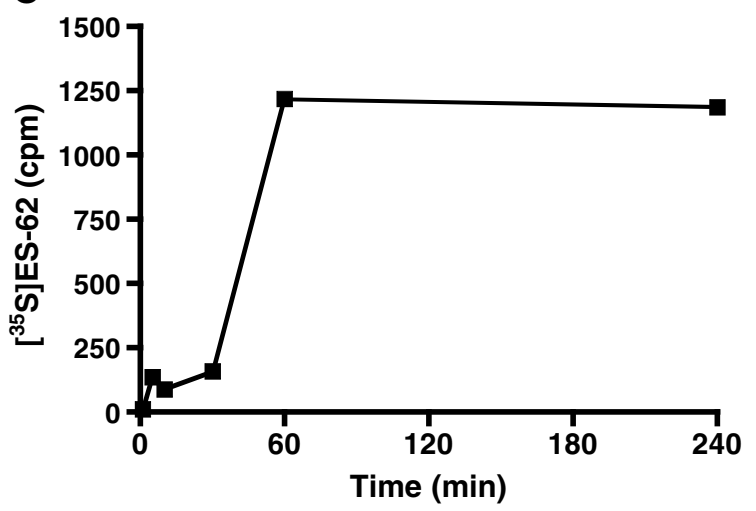

$\mathbf{F}$

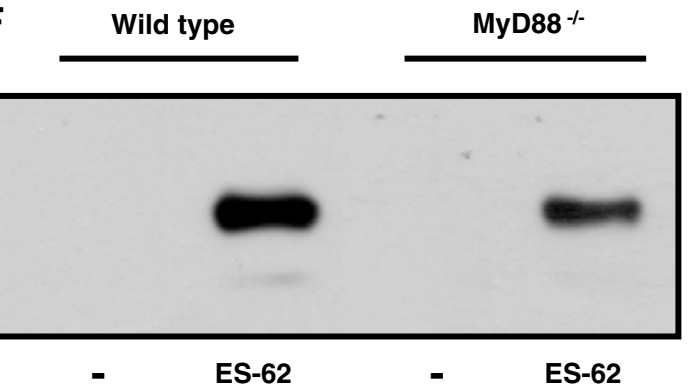

G

Wild type

TLR4 $^{-1-}$

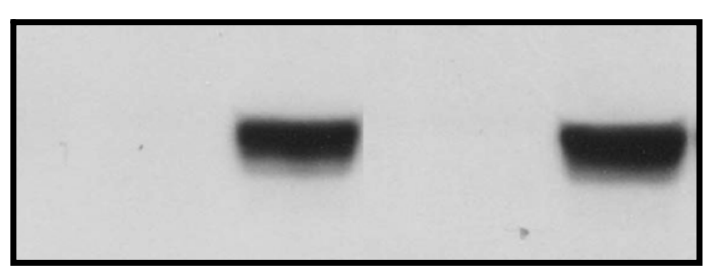

ES-62

ES-62

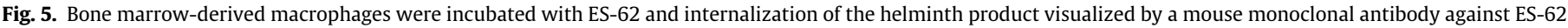

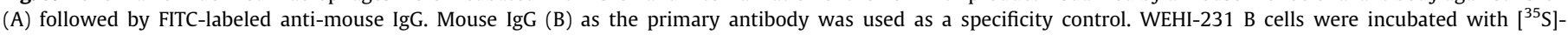

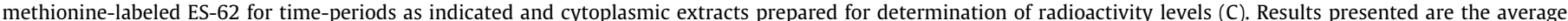

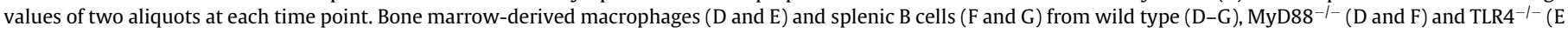
and G) mice were incubated with ES-62 at $37^{\circ} \mathrm{C}$. Following washing the binding and internalization of ES-62 was assessed by Western blot analysis.

cells of the immune system tend to internalize ES-62. Our previous studies have also revealed via the use of knockout mice that for ES62 to inhibit pro-inflammatory cytokine production by macrophages, the cells must express both TLR4 and MyD88 (Goodridge et al., 2005). TLR4 is present at the macrophage surface and hence similar to the situation with LPS, it may act as a receptor for ES-62. Consistent with this, ES-62 is bound and internalized by wild type and MyD88 ${ }^{-1-}$ macrophages but not TLR4 ${ }^{-1-}$ macrophages (Fig. 5D and E). However, ES-62 is internalized by each of wild type, ${\text { MyD } 88^{-1-} \text { and TLR4 }}^{-1-}$ splenic B cells (Fig. 5F and G). Thus, clearly the two cell types are using different receptors or combinations of receptors for ES-62 binding and internalization.

\section{Discussion}

ES-62 has been subject to study since 1989 and its immunomodulatory properties first documented in 1993 (reviewed by Harnett and Harnett (2009)). The first immunomodulatory study focused on the B cell and since then ES-62 has been studied with respect to $\mathrm{T}$ cells and $\mathrm{T}$ cell lines, B1 cells, macrophages, dendritic cells and mast cells (reviewed by Harnett and Harnett (2009)). The only cell population investigated that was found to be unaffected by exposure to ES-62 was human tonsil T cells (Harnett et al., 1998) and this could perhaps be explained by these cells failing to express the "ES-62 receptor". Subsequent work in APC that made use of knockout mice indicated that TLR4 expression was essential for the immunomodulatory action of ES-62 (Goodridge et al., 2005, 2007) and this was supported by knockdown studies in mast cells (Melendez et al., 2007). These studies therefore suggested that TLR4 was the receptor for ES-62. However they did not rule out the existence of co-receptors or other receptors for the helminth product and indeed there is evidence to suggest that ES-62 can bind to both the mannose receptor and the PAF receptor even although the biological significance of such interactions has yet to be established ((Goodridge et al., 2007) and unpublished results). Furthermore, it was unknown as to whether the critical role that TLR4 plays in facilitating ES-62 in APC and mast cells also applied to other cell types. Indeed Jurkat $\mathrm{T}$ cells are receptive to the 
actions of ES-62 (Harnett et al., 1998) but like primary T cells, apparently lack TLR4 (Ye and Gan, 2007).

We now illustrate apparent differences in receptor usage by ES62 on different cell types. Lymphocytes - both T and B cells, possess two surface-located ES-62-binding proteins of $\sim 135$ and $\sim 82 \mathrm{kDa}$ whereas U937 monocytes only express a molecule of $\sim 82 \mathrm{kDa}$. Based on blocking studies with free PC, interaction with both of these proteins in B cells is almost certainly via the PC moieties of ES-62. This may suggest a shared structural feature but the identity of the two proteins has yet to be established. Furthermore, based on Western blot analysis with anti-TLR antibodies the $82 \mathrm{kDa}$ protein being detected in B cells may be distinct from that in U937 and Jurkat T-cells, thereby increasing the number of possible ES-62 receptors in the immune system (in addition, Fig. 2 suggests that Jurkat cells may express an additional lower molecular mass receptor of $\sim 53 \mathrm{kDa}$ and Fig. 3 suggests the same of WEHI231 B cells). Although the Western blot data suggested that the $82 \mathrm{kDa}$ molecular weight protein in B cells could be TLR4, this could not be confirmed due to likely cross-reactivity amongst anti-TLR antibodies and hence the use of more specific antibodies or reagents may be warranted.

Binding of ES-62 to immune system cells results in internalization. ES-62 activity against APC is, as mentioned earlier, dependent on TLR4 and in the present study we indicate that the same is true for internalization. Thus, if the $82 \mathrm{kDa}$ molecule is not TLR4 then clearly it is not a receptor which is able to facilitate ES-62 internalization. The intracellular adaptor protein MyD88 is also necessary for ES-62 activity against APC (Goodridge et al., 2005) but unlike for TLR4, internalization of ES-62 is not dependent on expression of MyD88 suggesting that MyD88-dependent signaling is not essential for internalization. Absence of TLR4 did not prevent B cells from internalizing ES-62, raising the possibility of an alternative or additional receptor on these cells. It is tempting to speculate that this may be the $135 \mathrm{kDa}$ protein that is absent from U937 monocytes but this remains to be established. In any case, the data obtained with the two cell types clearly suggest that ES-62 as considered at the outset, interacts with different receptors on different cells of the immune system.

\section{References}

Deehan, M.R., Harnett, W., Harnett, M.M., 2001. A filarial nematode-secreted phosphorylcholine-containing glycoprotein uncouples the $\mathrm{B}$ cell antigen receptor from extracellular signal-regulated kinase-mitogen-activated protein kinase by promoting the surface Ig-mediated recruitment of Src homology 2 domain-containing tyrosine phosphatase-1 and Pac-1 mitogen-activated kinase-phosphatase. Journal of Immunology 166, 7462-7468.

Egan, C.A., Houston, K.M., Alcocer, M.J., Solovyova, A., Tate, R., Lochnit, G., McInnes, I.B., Harnett, M.M., Geyer, R., Byron, O., Harnett, W., 2006. Lack of immunological cross-reactivity between parasite-derived and recombinant forms of ES-62, a secreted protein of Acanthocheilonema viteae. Parasitology $132,263-274$

Everts, B., Hermelijn, H., Hokke, C.H., Yazdanbakhsh, M., 2010. Helminths and dendritic cells: sensing and regulating via pattern recognition receptors, Th2 and Treg responses. European Journal of Immunology 40, 1525-1537.

Feng, G.J., Goodridge, H.S., Harnett, M.M., Wei, X.Q., Nikolaev, A.V., Higson, A.P., Liew, F.Y., 1999. Extracellular signal-related kinase (ERK) and p38 mitogenactivated protein (MAP) kinases differentially regulate the lipopolysaccharidemediated induction of inducible nitric oxide synthase and IL-12 in macrophages: Leishmania phosphoglycans subvert macrophage IL-12 production by targeting ERK MAP kinase. Journal of Immunology 163, 64036412 .

Goodridge, H.S., Marshall, F.A., Else, K.J., Houston, K.M., Egan, C., Al-Riyami, L., Liew F.Y., Harnett, W., Harnett, M.M., 2005. Immunomodulation via novel use of TLR4 by the filarial nematode phosphorylcholine-containing secreted product, ES-62. Journal of Immunology 174, 284-293.

Goodridge, H.S., Marshall, F.A., Wilson, E.H., Houston, K.M., Liew, F.Y., Harnett, M.M. Harnett, W., 2004. In vivo exposure of murine dendritic cell and macrophage bone marrow progenitors to the phosphorylcholine-containing filarial nematode glycoprotein ES-62 polarizes their differentiation to an antiinflammatory phenotype. Immunology 113, 491-498.

Goodridge, H.S., McGuiness, S., Houston, K.M., Egan, C.A., Al-Riyami, L., Alcocer, M.J. Harnett, M.M., Harnett, W., 2007. Phosphorylcholine mimics the effects of ES-62 on macrophages and dendritic cells. Parasite Immunology 29, 127-137.

Harnett, M.M., Deehan, M.R., Williams, D.M., Harnett, W., 1998. Induction of signalling anergy via the $\mathrm{T}$-cell receptor in cultured Jurkat $\mathrm{T}$ cells by preexposure to a filarial nematode secreted product. Parasite Immunology 20, 551563.

Harnett, W., Harnett, M.M., 2009. Immunomodulatory activity and therapeutic potential of the filarial nematode secreted product, ES-62. In: Fallon, P.G. (Ed.) Advances in Experimental Medical Biology, Landes Bioscience, pp. 88-94.

Harnett, W., Harnett, M.M., 2010. Helminth-derived immunomodulators: can understanding the worm produce the pill? Nature Reviews Immunology 10, 278-284.

Haslam, S.M., Khoo, K.H., Houston, K.M., Harnett, W., Morris, H.R., Dell, A., 1997. Characterisation of the phosphorylcholine-containing N-linked oligosaccharides in the excretory-secretory $62 \mathrm{kDa}$ glycoprotein of Acanthocheilonema viteae. Molecular Biochemical Parasitology 85, 53-66.

Helmby, H., 2009. Helminths and our immune system: friend or foe? Parasitology International 58, 121-127.

Houston, K.M., Cushley, W., Harnett, W., 1997. Studies on the site and mechanism of attachment of phosphorylcholine to a filarial nematode secreted glycoprotein. Journal of Biological Chemistry 272, 1527-1533.

Katz, E., Lord, C., Ford, C.A., Gauld, S.B., Carter, N.A., Harnett, M.M., 2004. Bcl-(xL) antagonism of BCR-coupled mitochondrial phospholipase $A(2)$ signaling correlates with protection from apoptosis in WEHI-231 B cells. Blood 103 , 168-176.

Kigimoto-Ochiai, S., Noguchi, A., 2000. Two peptides from CD23, including the inverse RDG sequence and its related peptide, interact with MHC class Il molecule. Biochemical Biophysical Research Communications 267, 686-691.

Maizels, R.M., Holland, M.J., Falcone, F.H., Zang, X.-X., Yazdanbakhsh, M., 1999 Vaccination against helminth parasites - the ultimate challenge for vaccinologists? Immunological Review 171, 125-147.

Maizels, R.M., Yazdanbakhsh, M., 2003. Immune regulation by helminth parasites: cellular and molecular mechanisms. Nature Reviews Immunology 3, 733-744.

Melendez, A.J., Harnett, M.M., Pushparaj, P.N., Wong, W.S., Tay, H.K., McSharry, C.P. Harnett, W., 2007. Inhibition of FceRI-mediated mast cell responses by ES-62, a product of parasitic filarial nematodes. Nature Medicine 13, 1375-1381.

Mistrik, P., Moreau, F., Allen, J.M., 2004. Biacore analysis of leptin = leptin receptor interaction: evidence for a 1:1 stoichiometry. Analytical Biochemistry 327 271-277.

Moreau, E., Chauvin, A., 2010. Immunity against helminths: interactions with the host and the intercurrent infections. Journal of Biomedical Biotechnology (E. pub, Feb. 3).

Perrigoue, J.G., Marshall, F.M., Artis, D.A., 2008. On the hunt for helminthes: innate immune cells in the recognition and response to parasitic helminth parasites Cellular Microbiology 10, 1757-1764.

Romano Caratelli, C., Mazzola, N., Paolillo, R., Sorrention, S., Rizzo, A., 2010. Toll-like receptor 4 (TLR4) mediates human $\beta$-defensin-2 (HBD-2) in response to Chlamydia pneumoniae in mononuclear cells. FEMS Immunology Medical Microbiology 57, 116-124.

Smith, R.E., Patel, V., Seatter, S.D., Deehan, M.R., Brown, M.H., Brooke, G.P. Goodridge, H.S., Howard, C.J., Rigley, K.P., Harnett, W., Harnett, M.M., 2003. A novel MyD-1 (SIRP-1alpha) signaling pathway that inhibits LPS-induced TNFalpha production by monocytes. Blood 102, 2532-2540.

van Die, I., Cummings, R.D., 2009. Glycan gimickry by parasitic helminthes: a strategy for modulating the host immune response? Glycobiology 20, 2-12.

Ye, Z., Gan, Y.H., 2007. Flagellin contamination of recombinant heat shock protein 70 is responsible for its activity on T cells. Journal of Biological Chemistry 282 4479-4484. 